\title{
Affective Learning Outcomes Assessment as a Path to Online Dialogic Student Development
}

\author{
Vincent Nix \\ Lamar University
}

\author{
Misty Song \\ Lamar Institute of Technology
}

\author{
Robin Lindbeck \\ Idaho State University
}

\begin{abstract}
Meaning-centered education (Kovbasyuk \& Blessinger, 2013) suggests that students benefit from incorporating learning outcomes from non-cognitive domains. A radical idea in a world focused on standardization, this paradigm nevertheless holds great value for educators and students alike as we can never "find a behaviour or a state which is purely cognitive without affect nor a purely affective state without a cognitive element" (Piaget as cited in Clark \& Fiske, 1982, p.130). Infusing an online curriculum with weekly formative assessment activities allowed instructors to monitor students' states of mind while reducing negative emotional effects on learning by incorporating that feedback. Extended analysis promoted a deeper understanding of the roles that emotions and attitudes play in achieving affective learning outcomes.
\end{abstract}

Keywords: affective domain, affective learning domain, emotions, attitudes, formative assessment, meaning-centered learning, online learning

\section{INTRODUCTION}

For over two decades learning outcomes have been touted as critical evidence of educational effectiveness (NCHEMS, 2000). In August 2000, the Competency Standards Project: Another Approach to Accreditation Review was published on the Council for Higher Education Accreditation's (CHEA) website. The paper, describing a project set up by the National Center for Higher Education Management systems (NCHEMS), related how the project had ultimately recommended various types of assessments, but stressed that "at the best practice level, assessments ought to go beyond simple, single-person judgments" and should involve multiple raters. Cognitive learning-outcomes, based on "examination scores, performance assessments, and similar types of direct demonstrations" (NCHEMS, p.10) were recommended and subsequently, the results of those assessments have been critical components of college and university accreditation. Advances in educational assessment and evaluation techniques have made it possible to categorize cognitive achievements and convert them into countable groups; virtually everything 
that could conceivably be quantified is assessed for. Assessment is a rapid-growth profession and writing learning outcomes has become a science. However, this focus on the quantifiable cognitive element may have led to an obsession with teaching explicitly to cognitive outcome assessments, at the expense of other domains--particularly the affective one. An Internet search will yield numerous rubrics for measuring cognitive outcomes; relatively few are available for assessing affective learning outcomes. The National Institute of Learning Outcomes Assessment (NILOA) maintains a resource website of student-learning outcome-statement resources which has several external links. Among functional links on 5/27/2019, 100\% (17) referenced Bloom's Taxonomy and cognitive learning objectives, and there were zero explicit statements advocating for implementing affective learning domain outcomes. By 11/7/20 the functional links had increased to 20, but still only addressed cognitive domain outcomes, a bias which still persists as this article is submitted. Spady (1994) insisted that cognitive learning outcomes were not appropriate gauges of values, beliefs, attitudes, or psychological states of mind, and before that, Piaget observed that "...and in no state, even in the adult, can we find a behavior or a state which is purely cognitive without affect, nor a purely affective state without a cognitive element" (Piaget as cited in Clark \& Fiske, 1982, p.130). It would not be remiss to give equal focus to learning outcomes for the affective domain. Krathwohl, Bloom, and Masia (1964) defined the affective domain as:

Objectives which emphasize a feeling tone, an emotion, or a degree of acceptance or rejection. Affective objectives vary from simple attention to selected phenomena to complex but internally consistent qualities of character and conscience...objectives in the literature expressed as interests, attitudes, appreciations, values, and emotional sets of biases. (p. 7)

Despite numerous calls to action over decades of research, education remains laser-focused on cognitive learning outcomes. When affective learning is mentioned in the literature, researchers generally have generally only evaluated the second and third levels of the affective domain--or ignored those divisions entirely, treating the entire domain as a monolithic whole (McCroskey, 1994; Messman \& Jones-Corley, 2001). When affective domain measures are utilized, they are generally typically masked as students' cognitive self-report measures by students that represent affect toward the course or for the instructor (Bowman, 2010; Hooker \& Denker, 2014; Witt, Wheeless, \& Allen, 2004). Kovbasyuk and Blessinger (2013) called for assessing learning across all domains, as well as incorporating additional transdisciplinary learning; Norris and Weiss (2019), and Pekrun and Linnenbrink-Garcia (2014) encouraged further research with potential to achieve insight on how emotions might mediate learning in classroom settings, thereby influencing behavior; and Zahl et al. (2019) reported that the Center for the Advancement of Pharmacy Education advocated curricular change--particularly that would include concrete assessments of ALOs measuring the attitudes, skills, and values that are unique to the roles of professionals. Hansen (2019) maintained that assessing the whole student would have to include ALOs, such as growth mind-sets and social intelligence. She further explicated the need for drawing from other disciplines, such as sociology, psychology, anthropology, and behavioral economics. Going further, Kilgo, Sheets, \& Pascarella (2015) maintained that high-impact practices should also change students' attitudes and affective states. Ultimately, as Hundley, Kahn, Barbee, \& Partners (2019) asserted, if higher education hopes to improve the future of humanity, we must not continue to confine ourselves to cognitive learning outcomes; ALOs, based on reflection and introspection, must be integrated.

\section{CONCEPTUAL FRAMEWORK}

The researchers developed a mental model to illustrate the relationship between the elements that are critical to understanding affective learning, as shown in Figure 1. 


\section{FIGURE 1 \\ MENTAL MODEL OF THE RELATIONSHIPS BETWEEN VALUES, EMOTIONS, ATTITUDES, AFFECT, AND BEHAVIOR}

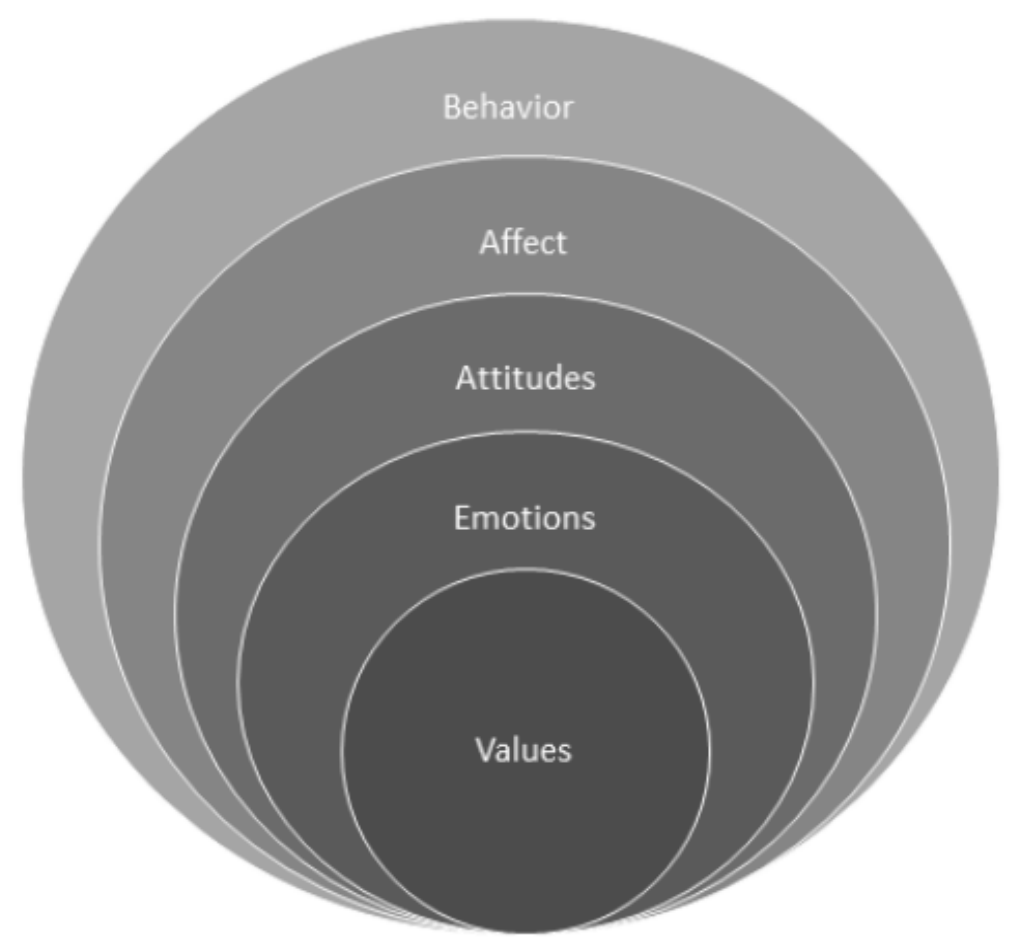

Nix \& Song (2020) presented this mental model based on research and practical experience in management, leadership, and training. We realized that each of those roles had different, yet related, desired outcomes: as trainers, we wanted better return on time invested; as team-managers, we wanted better performance; as leaders, we were responsible for instigating change or sustaining growth. This model incorporates the lessons learned in each of those roles and was ultimately designed to facilitate crosscultural and transnational learning in joint-venture settings. Students and clients approach us with their established sets of cultural and familial values, which can lead to unexpected conflict or inefficiency when those values collide with our own. Affective domain research that studies the relationships between emotions, attitudes, and behavior may help us better achieve both organizational goals and learning outcomes for training sessions, which then influences course learning outcomes. We share this mental model in the hope that our audience begins to understand the lenses through which we view the settings in which we collect and analyze data.

\section{Learning}

Salient to our discussion and the classroom environment, the authors relied heavily on Kovbasyuk and Blessinger's (2013) meaning-centered education and meaning-centered learning frameworks. Meaningcentered learning relies on the students' own viewpoints to inform content and structure, including the use of phenomenology, or the study of how students perceive and make sense of reality and their environment. Two constructs, in particular, guided the development of the course and learning activities: innovative teaching, and creative learning. The first stresses education through dialogue and collaboration with students, while creative learning places importance on giving students opportunities to be actively involved decision-makers, guiding their education, in an environment that employs numerous learning methods. This framework nests securely within a critical constructivism paradigm as defined by Kincheloe (2008). 


\section{Authentic Formative Assessment}

Schneider and Preckel (2017) conducted a systematic review of previous meta-analyses investigating 105 correlates associated with achievement in higher education. They determined that three particular variables were significant predictors of learner achievement: social interaction, meaningful learning, and assessment. The authors hold that assessment practices are particularly vital, as they inform any significant shift in institutional structures, especially when educational practices are undergoing significant change. An assessment system should be robust and include all elements of the course (Gatignon, Tushman, Smith, \& Anderson, 2002).

According to Schneider and Preckel (2017), "Teachers with high-achieving students invest time and effort in designing the microstructure of their courses, establish clear learning goals, and employ feedback practices" (p. 565). Teachers should guide learning by responding to students' performances, as real-time authentic formative assessments inform instructors what their students know and when they know it —and, thus by extension, also show where comprehension is lacking. Pertinent to this study, Simonson et al. (2015) recommended using Kirkpatrick's (1994) evaluation framework for use in distance education as a method of student-learning assessment.

\section{Online Learning Pedagogy}

A doctoral strategic-planning course, designed for online instruction, was developed with Salmon's (2013) five-stage learning model integrated into the curriculum. Pertinent to this study are the fourth and fifth stages of her model, which address how learners might construct and utilize knowledge:

- In the fourth stage, learners are comfortable working in the online environment; the learning management system is freely utilized for conferencing, collaborative learning exercises, and team projects, and knowledge is created through these activities.

- In the fifth stage, learners are content with and have synthesized their newfound knowledge and use it to set goals, discover, reflect, and present information to others with confidence.

\section{Evolution of Learning Theories}

Over time, learning theories have moved away from the classical conditioning model to incorporate more humanistic elements. In the early years, affective learning was not considered important, and even as late as 1987 Dr. Skinner said in an interview with the New York Times (Goleman, 1987):

\section{If I had it all to do again, I would still call the mind a black box; I would not use any of the new techniques for measuring information processing and the like. My point has always been that psychology should not look at the nervous system or so-called mind - just at behavior.}

An evident trend demonstrates increasing focus on the intersectionality of personal, social, and cultural factors. A growing understanding that each person has a different interpretation and construction of knowledge naturally leads to the realization that the learner is not a blank slate but brings past experiences and cultural factors to a situation. Bringing this understanding into the complex phenomenon of learning leads to what Kincheloe, 2004 terms "critical constructivism." In contrast with objectivist philosophies (think Aristotle or Locke) that claim knowledge and reality are independent from human minds, this new paradigm holds that dialogue is necessary to achieve mutual understanding, as knowledge is not simply something external, but attained through a cultural and emotional lens. This framework attempts to destroy unequal power imbalances that reproduce the status quo. To wit, critical constructivism:

- Encourages greater personal and social consciousness, helping to develop freedom of thought that recognizes authoritarian tendencies and connects knowledge to power.

- Motivates people to take constructive action, including repair work or de-construction of undesired structures. 
- Theorizes that the connection between power and knowledge maintains the status quo, anointing certain groups and institutions as the gatekeepers of knowledge.

- Holds that powerful groups and influential people maintain their knowledge construction hegemony by continually undermining alternative routes to learning.

Meaning-centered education and meaning-centered learning, taken together as a framework, illustrate where we should strive to be operating as the critical constructivist paradigm evolves. When we examine the structures and institutions we've built around knowledge and knowing, do we find that they serve as a public good? Does knowledge benefit all members of society, or only a few select groups or organizations. If we find the latter holds true, then further deconstruction and reconstruction work is necessary. Gredler (2009) claimed that in a justice-minded framework, learning theories should consider the intersection of personal, social, and cultural factors. Thus, both micro-and macro-level examinations are necessary to achieve holistic learning, as discrepancies exist within, and tensions subsist between, the classic theoretical foundations.

Kovbasyuk and Blessinger (2013) define meaning-centered education (MCE) as an "approach that facilitates the conscious integration of new [and] prior learning across all domains based on personal meanings about oneself in relation to the world" (p.20). In the same volume they defined meaning-centered learning (MCL) as "a human centered approach that facilitates the holistic integration of all learning domains... through diverse life contexts, which motivates learners to apply meaning-based principles" in their own lives (p.18), describing how MCL fosters self-determined personalities and self-evolution, through multiple dimensions of meaning-making including phenomenological, philosophical, psychological, and sociological.

\section{Affective Learning}

Affective domain learning-outcomes should be added to courses because current methods and cognitive assessment practices do not account for the dimension of affective learning Krathwohl et al. (1964) called "characterization by a value or value sets" (p. 184). The affective taxonomy levels are "ordered according to the principle of internalization... the process whereby a person's affect... [grows] to a point where the affect is 'internalized' and consistently guides or controls the person's behavior" (Seels \& Glasgow, 1990, p. 28). This focus on the affective learning domain stands in stark contrast to the cognitive-focused model, with vastly different goals for learners that sit atop the two models of learning: mental tasks are the desired outcomes of cognitive learning, whereas states of mind - affects - are the focus for affective learning. An affect, which stems from context and experience, can be classified as constructive, positive, or contrary (Arora \& Sharma, 2018). For example, a long-term contrary affect may lead to an affective disorder, like depression. Positive affect may encourage cooperation and is prompted by increasing positive emotions such as joy and happiness. Constructive affect can foster a growth mindset and could be useful for organizational change-agents. The taxonomy recognizes five levels; Figure 2 illustrates the affective learning taxonomy domain levels and the assumptions that accompany each level. 
FIGURE 2

THE AFFECTIVE LEARNING DOMAIN

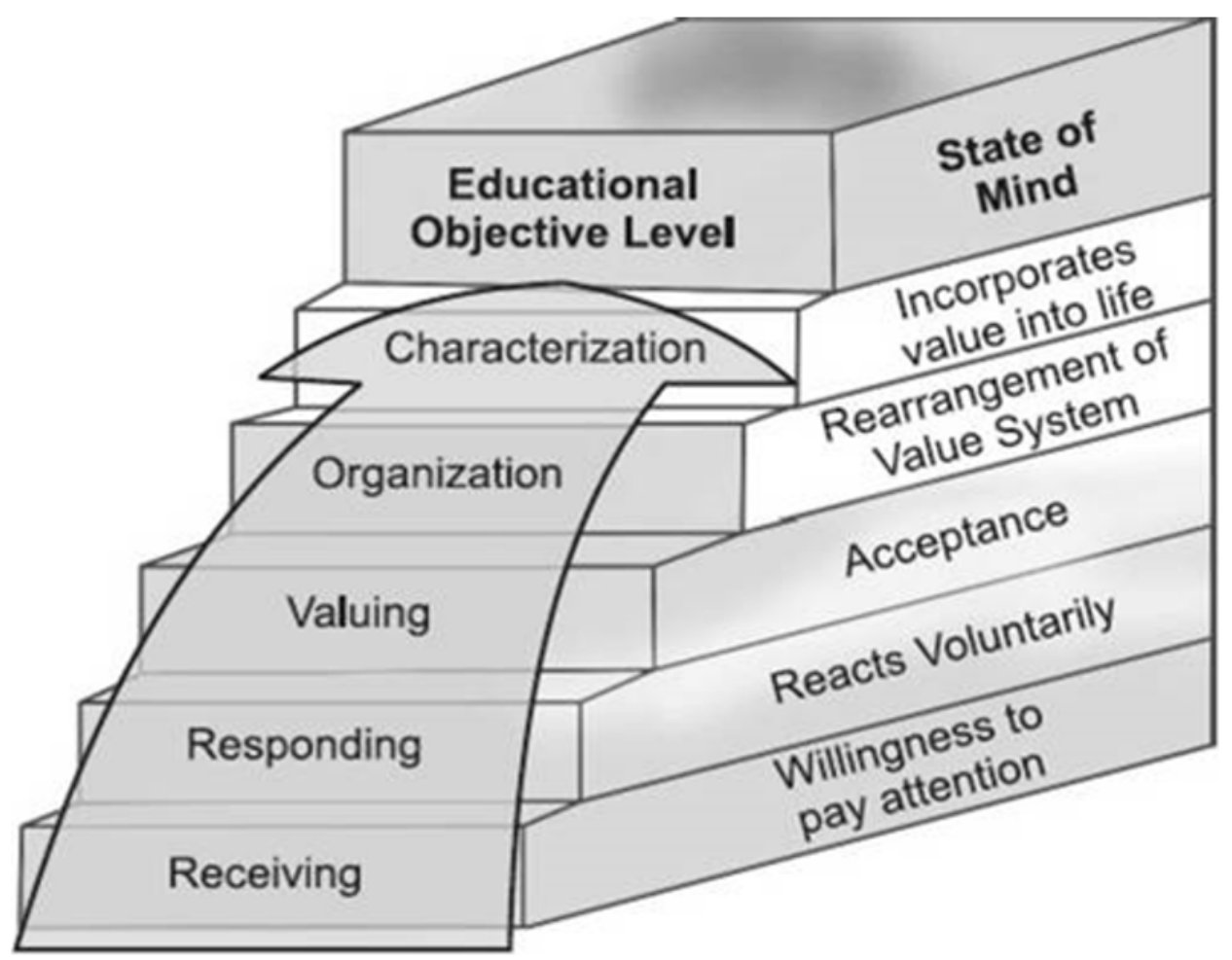

Note: image from open-source textbook at

https://ebrary.net/2967/management/basic_levels_learning_domains_learning

The affective domain was often viewed as a hindrance to learning and was researched and described in literature for years as something that should be controlled for or eliminated. Edward DeBono's "Six Thinking Hat" model (DeBono, 1985) illustrates that remarkably well; in that model, he used different colors of hats to represent different modes of thinking, using red hats to represent affective thinking, portraying red hats as emotional folks, unbridled by reason. Indeed, during annual faculty reviews, many of us are forced to decide whether affective responses have undue influence on course ratings; some would argue that the reviews themselves are of little value because they primarily measure affective factors rather than cognitive learning.

\section{Emotions}

Baumeister and Bushman (2007) conceptualized the experience of an emotion as "a subjective state, often accompanied by a bodily reaction (e.g., increased heart rate) and an evaluative response to some event" (p. 61). Emotions include reactions and judgments as interactive core elements, and research recognizes that behavior stems from attitudes, which are in turn formed from values (Izard, 2010). Studies examining what happens between values-adoption and attitude-formation has identified the most powerful emotions, in terms of the consequences they may have on an individual's productivity (Ortony \& Turner, 1990) or propensity to learn, and a clear picture of positive and negative emotions has emerged. Over longer periods of time, repeated exposure to conditions that elicit these emotions have lasting and significant effects on attitude formation and may dictate behavior. Among the positive emotions, joy, satisfaction, and contentment have the greatest impact on behavior, while anxiety, fear, and confusion have the most detrimental effects. Immordino-Yang and Damasio (2007) suggested that emotions are attached to learning 
in the classroom and become part of how the acquired information is retrieved thereafter, suggesting that the affective domain is intimately bound up with learning and academic success.

\section{Attitudes}

Functional attitude theory was developed in the 1950s by two separate groups of researchers (Katz, 1960; Smith, Bruner, \& White, 1956). Despite working separately, they derived similar lists of functional attitudes, and the parallels solidified both frameworks as the de facto paradigm for more than two decades (Snyder \& DeBono, 1985). It should be noted that when Katz defined his categories, he did not offer any method for incorporating his constructs when conducting empirical research. It fell to others (Debono, 1987; Debono, 2000; Herek, 1986, 1987, 2000; Locander \& Spivey, 1978; Petty \& Wegener, 1998; Shavitt, 1990; Shavitt, Swan, Lowrey, \& Wanke, (1994) to devise clever and creative methods to use Katz' attitude construct in research projects. Our research, conducted using Katz' original framework, employed his four categories of attitudes as a controlled nuisance variable; attitude was an exploratory factor.

\section{RESEARCH SETTING}

The authors are primarily focused on exploring what it means to incorporate affective learning outcomes (ALOs) alongside cognitive learning outcomes (CLOs) into classrooms, extracurricular student development programs, and assessment efforts. At the base affective learning-objective level, learners must be willing (and able - so we must consider accessibility here too) to pay attention. Once that attention is established, then learners are able to receive the information that we as instructors are attempting to transmit. As students work toward the pinnacle learning objective level, their goals transform into something vastly different. In the familiar cognitive-learning taxonomy, the top levels represent mental tasks, which stands in stark contrast to the top affective-learning levels where the goal is a state of mind, or an affect.

\section{Procedures}

The researchers employed focused comparisons of mixed data from previously completed course assessments. According to Salkind (2010), this fits into a post-hoc or a posteriori analysis framework. Quantitative data were collected from the Level 1 evaluations via ordered response items, while qualitative data were collected from the Level 2 evaluations via students' reflective formative assessment prompts. Simonson, Smaldino, \& Zvacek, (2015) recommended Kirkpatrick's (1994) evaluation framework for use in distance education. The researchers have experience working in HRD development and are intimately familiar with the four levels of evaluation. To begin with, Level 1 evaluations measure reaction to the learning event, course materials, and a trainer's perceived likeability or effectiveness; the Level 1 evaluation construct is an indirect measure. However, Level 2 evaluations explore respondents' deeper reflections and offer direct evidence of learning. The evaluation levels are listed below, preceded by their shorthand labels, as in Simonson et al.:

1. Reaction-Did they like it?

2. Learning-Did they learn it?

3. Transfer-Will they use it?

4. Results-Will it matter?

5. Return on investment (ROI) —Was it worth the cost? (pp. 308-309)

For this study, ordered response items were used, allowing students to self-rate their relative agreement with five statements, corresponding to five elements of the course:

- The learning activities were effective.

- Instructions were clear and easy to follow.

- I learned something I had not known before this week.

- The learning activities were engaging.

- I struggled with comprehension for this week's learning activities. 
The primary rationale for including the formative assessments from Level 1 evaluations in the course was so that instructors could improve instruction after a summative evaluation of weekly ratings. The researchers developed and introduced this course (Strategic Planning for Resource Allocation) as part of a Doctor of Education (EdD) educational leadership program, drawing on their experience and research, and specifically designed the curriculum with the idea that students would want to become agents of change, either as executives or consultants. Based on earlier research regarding the need to assess reactions to change (Gatignon et al., 2002), the instructors implemented weekly formative assessment into the course. Data from these items were analyzed using the Minitab statistical analysis program.

The Level 2 evaluations allowed instructors to reinforce specific learning topics if students self-reported that they had not mastered them. As students responded with their muddiest points, the instructors modified the material for the next virtual meeting after coding and clustering the comments. In essence, the students were determining the content of each course meeting; they were embodying Salmon's (2013) idea that students, as they reach the fifth and highest stage of learning in her model, can both direct their own learning as well as serve as facilitators of learning for others. Learning activities should be "centered on participants gaining self-insight through reflecting and making judgements about their newly acquired knowledge" (p. 34). The Level 2 evaluation prompt asked students to examine the most interesting or the most useful constructs from their learning activities, if there were no muddy points. We included an ALO with the course learning outcomes (CLOs):

- Characterize organizations through analyses of strategic plans.

Researchers coded textual data using the MAXQDA qualitative data analysis software. The data itself came from weekly responses, first from Level-1 satisfaction surveys, and later from Level-2 reflective posts authored by the students. The responses from the Level- 2 evaluation prompts were imported into the software. The course's lead instructor coded each open-ended response for evidence of emotions and attitudes, after which two of the authors independently coded data for affective learning at two levels: 1) evidence of affective learning and 2) level of affective learning. The Griffith University Affective Learning Scale (GUALS; Rogers, Mey, Chan, Lombard \& Miller, 2018) was utilized for second-level coding, with permission from the authors.

Nested within the organizational institutionalism framework are several classic sociological theories that offer interesting and exciting ways to re-invigorate how those works are viewed. Tucked away nearly hidden in the theories of practice we find such a gem. Harold Garfinkel's ethnomethodology (1967) offers that reality is only knowable by how participants restore order after a breach event. Participants will continue restorative work until their actions and the organizational procedures are publicly accountable. COVID-19, if we want to find a silver lining, was the great breach-event. Assessing student reflections as they were navigating several crises during 2020 allowed course instructors opportunities to peer into a world not often seen. Responding to students contextually began to deepen dialog. Learning was occurring for instructors, too, although that is beyond the scope of this research report.

\section{Population Characteristics}

Two doctoral cohorts, over two years, provided data for this study. Seventy percent $(n=84)$ of the students were women. Cohort one consisted of 56 students (39 women and 17 men) while cohort two included 64 students ( 45 women and 19 men) registered for the Strategic Planning and Resource Allocation course; seventy percent were women $(n=84)$. Eighty percent were working in primary and secondary education (K-12), and 15\% worked in tertiary education. Five percent of the students worked in nonprofit and for-profit organizations outside the education industry, including active-duty military-officer personnel. All students were tasked to complete Level 1 and 2 evaluations each week. After both 8-week courses there were 838 responses to the evaluations. Table 1 displays the distribution of the GUALS score statistics by industry. 

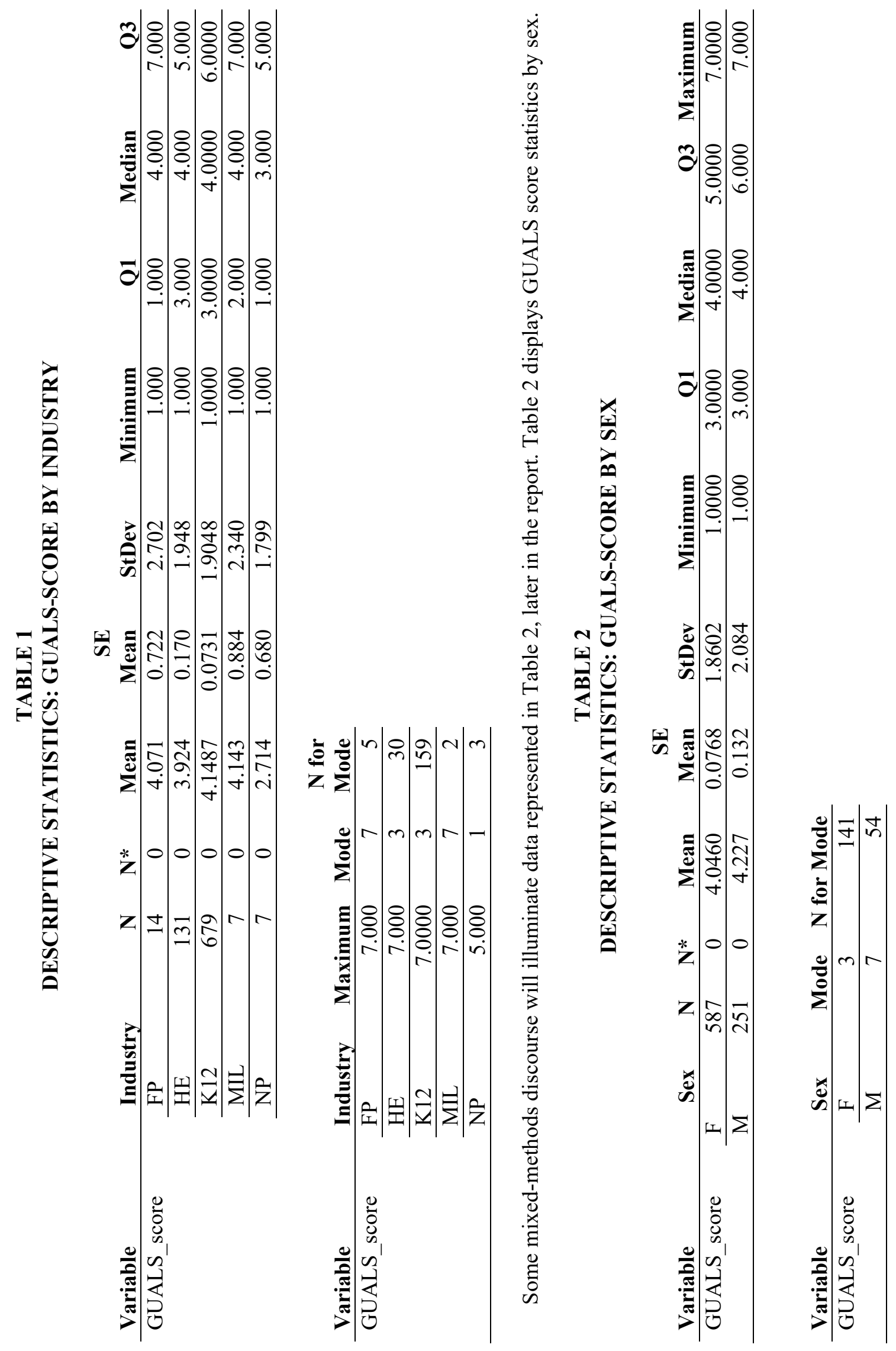

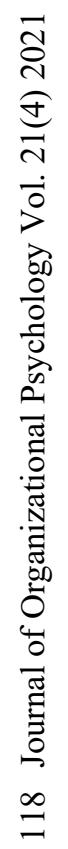




\section{DATA ANALYSIS}

Multiple levels of analyses were performed on the course assessment data. Each analysis is detailed in the following sections.

\section{Level 1 Evaluations}

For the Level 1 evaluations, ordered response prompts on a scale of 1 (strongly disagree) to 4 (strongly agree) were used to collect self-reported student satisfaction data. Five prompts were labeled as follows:

- The learning activities were effective.

- The instructions were clear and easy to follow.

- I learned something I had not known before this week.

- The learning activities were engaging this week.

- I struggled with comprehension of this week's learning activities.

Table 3 provides tallies for seven weeks of data.

TABLE 3

\section{DESCRIPTIVE STATISTICS FOR LEVEL ONE EVALUATIONS}

\begin{tabular}{|c|c|c|c|c|c|c|c|c|}
\hline Variable & Week & Mean & StDev & Median & Q3 & Range & Mode & $\begin{array}{l}\text { N for } \\
\text { Mode }\end{array}$ \\
\hline \multirow[t]{7}{*}{ Effective Activities } & 1 & 3.5893 & 0.6086 & 4.0000 & 4.0000 & 3.0000 & 4 & 71 \\
\hline & 2 & 3.5082 & 0.6833 & 4.0000 & 4.0000 & 3.0000 & 4 & 72 \\
\hline & 3 & 3.0826 & 0.8523 & 3.0000 & 4.0000 & 3.0000 & 3 & 60 \\
\hline & 4 & 3.2295 & 0.7017 & 3.0000 & 4.0000 & 3.0000 & 3 & 59 \\
\hline & 5 & 3.3504 & 0.6475 & 3.0000 & 4.0000 & 3.0000 & 3 & 60 \\
\hline & 6 & 3.3934 & 0.6371 & 3.0000 & 4.0000 & 3.0000 & 3,4 & 57 \\
\hline & 7 & 3.4083 & 0.6798 & 3.0000 & 4.0000 & 3.0000 & 4 & 59 \\
\hline \multirow[t]{7}{*}{ Clear Instructions } & 1 & 3.3571 & 0.7694 & 4.0000 & 4.0000 & 3.0000 & 4 & 58 \\
\hline & 2 & 3.2705 & 0.8135 & 3.0000 & 4.0000 & 3.0000 & 4 & 59 \\
\hline & 3 & 2.8843 & 0.9054 & 3.0000 & 4.0000 & 3.0000 & 3 & 54 \\
\hline & 4 & 3.0246 & 3.0246 & 3.0000 & 4.0000 & 3.0000 & 3 & 52 \\
\hline & 5 & 3.4483 & 0.6896 & 4.0000 & 4.0000 & 3.0000 & 4 & 63 \\
\hline & 6 & 3.4016 & 0.6883 & 3.5000 & 4.0000 & 3.0000 & 4 & 61 \\
\hline & 7 & 3.3529 & 0.7200 & 3.0000 & 4.0000 & 3.0000 & 4 & 56 \\
\hline \multirow[t]{7}{*}{ Learned, Something New } & 1 & 3.7411 & 0.5154 & 4.0000 & 4.0000 & 2.0000 & 4 & 87 \\
\hline & 2 & 3.6803 & 0.5342 & 4.0000 & 4.0000 & 2.0000 & 4 & 87 \\
\hline & 3 & 3.6777 & 0.5946 & 4.0000 & 4.0000 & 3.0000 & 3 & 88 \\
\hline & 4 & 3.5738 & 0.5442 & 4.0000 & 4.0000 & 2.0000 & 4 & 73 \\
\hline & 5 & 3.3761 & 0.7038 & 3.0000 & 4.0000 & 3.0000 & 3 & 57 \\
\hline & 6 & 3.4590 & 0.6318 & 4.0000 & 4.0000 & 3.0000 & 3 & 64 \\
\hline & 7 & 3.3361 & 0.6545 & 3.0000 & 4.0000 & 3.0000 & 3 & 61 \\
\hline \multirow[t]{7}{*}{ Engaging Activities } & 1 & 3.5045 & 0.5844 & 4.0000 & 4.0000 & 2.0000 & 4 & 65 \\
\hline & 2 & 3.5328 & 0.5776 & 4.0000 & 4.0000 & 2.0000 & 4 & 70 \\
\hline & 3 & 3.0909 & 0.8466 & 3.0000 & 4.0000 & 3.0000 & 3 & 58 \\
\hline & 4 & 3.2131 & 0.8453 & 3.0000 & 4.0000 & 3.0000 & 4 & 53 \\
\hline & 5 & 3.2564 & 0.7090 & 3.0000 & 4.0000 & 3.0000 & 3 & 54 \\
\hline & 6 & 3.3279 & 0.6485 & 3.0000 & 4.0000 & 2.0000 & 3 & 58 \\
\hline & 7 & 3.3083 & 0.6957 & 3.0000 & 4.0000 & 3.0000 & 3 & 60 \\
\hline
\end{tabular}




\begin{tabular}{lllllllll}
\hline Struggled w/Comprehension & 1 & 1.6518 & 0.7192 & 2.0000 & 2.0000 & 3.0000 & 1 & 54 \\
\cline { 2 - 8 } & 2 & 2.1148 & 1.0617 & 2.0000 & 3.0000 & 3.0000 & 1 & 46 \\
\cline { 2 - 8 } & 3 & 2.7769 & 1.0447 & 3.0000 & 4.0000 & 3.0000 & 3 & 47 \\
\cline { 2 - 8 } & 4 & 2.4262 & 1.0359 & 3.0000 & 3.0000 & 3.0000 & 3 & 42 \\
\cline { 2 - 8 } & 5 & 2.0085 & 0.9604 & 2.0000 & 3.0000 & 3.0000 & 1 & 45 \\
\cline { 2 - 8 } & 6 & 1.8607 & 0.8655 & 2.0000 & 3.2500 & 3.0000 & 1 & 51 \\
\cline { 2 - 8 } & 7 & 1.9333 & 0.9503 & 2.0000 & 3.7500 & 3.0000 & 1 & 48 \\
\hline
\end{tabular}

A higher median/mean/mode score was desired on each item, except for the fifth prompt, "I struggled with comprehension;" it was hoped that students would strongly disagree or at least disagree with that statement in most cases.

\section{Level 2 Evaluations}

Emotions

It should be noted that the authors incorporated confusion into our coding and classification. While we have since learned that there is considerable debate about whether confusion should be characterized as an emotion or as "disequilibrium in cognitive processing" (Tyng, Amin, Saad, \& Malik, 2017), we began this project as a mechanism for improving our teaching, and, alas, had designed the study to include the concept of confusion. Therefore, we acknowledge the uncertain classification, while continuing to code for confusion. Similarly, we noted in a different study (Nix, Shelton, \& Song, forthcoming) that there seemed to be different sorts of anxiety. We had found that one type of recurring emotion seemed to fall short of excitement but did not quite fall into the category of worry either. Coders decided to code ANW for anxiety, no worry to explore. Table 4 presents the tally for each primary emotion coded in segments of text throughout both eight-week online courses. Additional mixed-data analysis will provide further insight, later in our report.

TABLE 4

TALLY FOR DISCRETE VARIABLES: PRIMARY_EMOTION

\begin{tabular}{|c|c|c|c|c|}
\hline Primary_emotion & Count & Percent & Cumulative Count & CumPct \\
\hline AN & 5 & 0.60 & 5 & 0.60 \\
\hline ANW & 90 & 10.74 & 95 & 11.34 \\
\hline AP & 30 & 3.58 & 125 & 14.92 \\
\hline AW & 167 & 19.93 & 292 & 34.84 \\
\hline$C F$ & 36 & 4.30 & 328 & 39.14 \\
\hline $\mathrm{CN}$ & 359 & 42.84 & 687 & 81.98 \\
\hline $\mathrm{D}$ & 6 & 0.72 & 693 & 82.70 \\
\hline GS & 4 & 0.48 & 697 & 83.17 \\
\hline $\mathrm{H}$ & 12 & 1.43 & 709 & 84.61 \\
\hline $\mathrm{J}$ & 19 & 2.27 & 728 & 86.87 \\
\hline $\mathrm{S}$ & 109 & 13.01 & 837 & 99.88 \\
\hline SD & 1 & 0.12 & 838 & 100.00 \\
\hline $\mathrm{N}=$ & 838 & & & \\
\hline
\end{tabular}

\section{Attitudes}

Four attitudes were evident after the Level 2 responses were analyzed. From Katz's (1960) Categories, ego-defensive (E), knowledge (K), utilitarian (U), and value-expressive (V) were coded. Table 5 provides the frequency of each functional attitude category across the two cohorts. There were significant differences between the cohorts that will be discussed later in the report. 
TABLE 5

TALLY FOR DISCRETE VARIABLES: ATTITUDE

\begin{tabular}{rrrrr}
\hline Attitude & Count & Percent & Cumulative Count & CumPct \\
\hline $\mathrm{E}$ & 222 & 26.49 & 222 & 26.49 \\
\hline $\mathrm{K}$ & 412 & 49.16 & 634 & 75.66 \\
\hline $\mathrm{U}$ & 73 & 8.71 & 707 & 84.37 \\
\hline $\mathrm{V}$ & 131 & 15.63 & 838 & 100.00 \\
\hline $\mathrm{N}=$ & 838 & & & \\
\hline
\end{tabular}

Affective Learning Outcomes

Two researchers analyzed the open-ended text responses from the Level 2 evaluations. While the ALO was at the hierarchical top level of "characterization," any evidence of affective learning was still coded as the students' reflective pieces were read and reviewed. The researchers autonomously coded the levels of affective learning according to the GUALS (Rogers et al., 2018), illustrated in Figure 3.

FIGURE 3

GRIFFITH UNIVERSITY AFFECTIVE LEARNING SCALE (GUALS)

\begin{tabular}{|c|c|c|c|c|c|c|}
\hline $\mathbf{1}$ & $\mathbf{2}$ & $\mathbf{3}$ & $\mathbf{4}$ & $\mathbf{5}$ & $\mathbf{6}$ & $\mathbf{7}$ \\
\hline $\begin{array}{c}\text { No evidence } \\
\text { of affective } \\
\text { learning }\end{array}$ & 'Receiving' & 'Responding' & 'Valuing' & 'Organisation' & & 'Characterisation' \\
\hline
\end{tabular}

Note: image used with permission of author.

Note that the GUALS has a seven-point ordered scale for rating the six levels of affective learning. Table 6 presents the results of those coded data.

TABLE 6

GUALS-SCORE STATISTICS ACROSS BOTH COHORTS BY WEEK (LEARNING MODULE)

$\underline{\text { Statistics }}$

\begin{tabular}{lllllllll} 
Variable & Week & Mean & StDev & Median & Q3 & Range & Mode & N for Mode \\
\hline GUALS_scores & & & & & & & & \\
& 1 & 3.446 & 2.004 & 3.000 & 5.000 & 6.000 & 1 & 28 \\
\cline { 2 - 9 } & 2 & 3.943 & 1.925 & 4.000 & 5.000 & 6.000 & 3 & 28 \\
\cline { 2 - 8 } & 3.744 & 1.429 & 4.000 & 5.000 & 6.000 & 3 & 38 \\
\hline 4 & 4.309 & 1.913 & 5.000 & 6.000 & 6.000 & 3 & 33 \\
\hline & 4.458 & 2.127 & 4.500 & 7.000 & 6.000 & 7 & 33 \\
\hline & 6 & 4.615 & 2.035 & 5.000 & 7.000 & 6.000 & 7 & 32 \\
\hline
\end{tabular}

Intra-rater reliability was assessed using Minitab; Fleiss' kappa was 0.93 (95\% Cl: 0.92--0.96) for rater agreement. This increased from our earlier study (Nix et al. forthcoming) and indicates researchers reliably become more familiar with coding for affective learning with additional practice. Table 7 provides a snapshot. 
TABLE 7

INTRA-RATER RELIABILITY

\section{Between Appraisers Assessment Agreement}

\begin{tabular}{|c|c|c|c|}
\hline \#Inspected & \#Matched & Percent & $95 \%$ CI \\
\hline 838 & 792 & 94.51 & $(92.75,95.95)$ \\
\hline
\end{tabular}

\#Matched: All appraisers' assessments agree with each other.

Fleiss' Kappa Statistics

\begin{tabular}{lrrrr} 
Response & Kappa & SE Kappa & $\mathbf{Z}$ & P(vs>0) \\
\hline 1 & 0.91525 & 0.0345444 & 26.4951 & 0.0000 \\
\hline 2 & 0.65154 & 0.0345444 & 18.8608 & 0.0000 \\
\hline 3 & 0.90054 & 0.0345444 & 26.0691 & 0.0000 \\
\hline 4 & 1.00000 & 0.0345444 & 28.9482 & 0.0000 \\
\hline 5 & 0.99625 & 0.0345444 & 28.8397 & 0.0000 \\
\hline 6 & 0.99355 & 0.0345444 & 28.7616 & 0.0000 \\
\hline 7 & 1.00000 & 0.0345444 & 28.9482 & 0.0000 \\
\hline Overall & 0.93484 & 0.0147045 & 63.5747 & 0.0000 \\
\hline
\end{tabular}

It is evident that the highest affective learning outcome attainment occurred in weeks four, five, and six; raters strongly agreed. However, cohort-two learning outcomes data was rated higher over the first two units. Conversely, cohort-one learning outcomes data reflected higher GUALS scores in weeks three through seven. That finding was unexpected, after the analysis included in the forthcoming report, and will be examined below. Table 8 presents this data.

TABLE 8

\section{GUALS-SCORE STATISTICS BY COHORT AND BY WEEK (LEARNING MODULE)}

Results for Cohort $=1$

$\underline{\text { Statistics }}$

\begin{tabular}{llrrrrrrr} 
Variable & Week & Mean & StDev & Median & Q3 & Range & Mode & N for Mode \\
\hline GUALS_scores & 1 & 3.218 & 2.052 & 3.0000 & 5.0000 & 6.0000 & 1 & 18 \\
\cline { 2 - 9 } & 2 & 3.786 & 1.856 & 4.0000 & 5.0000 & 6.0000 & 3 & 13 \\
\cline { 2 - 9 } & 3 & 3.818 & 1.156 & 4.0000 & 5.0000 & 6.0000 & 4 & 19 \\
\cline { 2 - 9 } & 5.357 & 1.600 & 5.0000 & 7.0000 & 6.0000 & 7 & 20 \\
\cline { 2 - 9 } & 5.255 & 1.974 & 6.0000 & 7.0000 & 6.0000 & 7 & 25 \\
\hline & 6 & 5.418 & 1.707 & 6.0000 & 7.0000 & 6.0000 & 7 & 24 \\
\hline
\end{tabular}

Results for Cohort $=2$

$\underline{\text { Statistics }}$

\begin{tabular}{llrrrrrrr} 
Variable & Week & Mean & StDev & Median & Q3 & Range & Mode & N for Mode \\
\hline GUALS_scores & 1 & 3.667 & 1.949 & 3.000 & 5.000 & 6.000 & 3 & 13 \\
\cline { 2 - 9 } & 2 & 4.076 & 1.987 & 5.000 & 5.250 & 6.000 & 5 & 18 \\
\cline { 2 - 9 } & 3 & 3.682 & 1.628 & 3.000 & 5.000 & 6.000 & 3 & 21 \\
\cline { 2 - 9 } & 4 & 3.433 & 1.708 & 3.000 & 5.000 & 6.000 & 3 & 25 \\
\cline { 2 - 9 } & 3.762 & 2.022 & 4.000 & 6.000 & 6.000 & 1,3 & 11 \\
\cline { 2 - 9 } & 6 & 3.955 & 2.056 & 4.000 & 6.000 & 6.000 & 5 & 15 \\
\hline
\end{tabular}




\section{RESULTS OF DATA ANALYSES}

Researchers utilized both fixed-effects and general linear model routines in Minitab. For any variable that appeared to have a statistically significant impact, we performed an individual Kruskal-Wallis test. Table 9 presents the statistics for attitude.

TABLE 9

DESCRIPTIVE STATISTICS, GUALS-SCORE

\begin{tabular}{llrrrrrrr}
\multirow{2}{*}{ Variable } & Week & Mean & StDev & Median & Q3 & Range & Mode & N for Mode \\
\hline GUALS_scores & $\mathrm{E}$ & 2.5405 & 1.2854 & 3.0000 & 3.0000 & 6.0000 & 3 & 92 \\
\cline { 2 - 9 } & $\mathrm{K}$ & 4.9879 & 1.6006 & 5.0000 & 6.0000 & 6.0000 & 5 & 118 \\
\cline { 2 - 9 } & $\mathrm{U}$ & 2.644 & 1.759 & 2.000 & 4.000 & 6.000 & 1 & 28 \\
\cline { 2 - 9 } & $\mathrm{V}$ & 4.763 & 1.758 & 5.000 & 6.000 & 6.000 & 5 & 33 \\
\hline
\end{tabular}

Knowledge attitudes appear to serve as powerful catalysts of affective learning; ego-defensive attitudes, in particular, served as extreme barriers to affective learning. These trends were indicated previously in the forthcoming report. A Kruskal-Wallis test (see Table 10) verified that there were highly significant $H(3,838)=290.66, p=0.00$ differences between the median scores.

TABLE 10

KRUSKAL-WALLIS TEST: GUALS-SCORE VERSUS ATTITUDE

Descriptive Statistics

\begin{tabular}{lrrrr} 
Attitude & N & Median & Mean Rank & Z-Value \\
\hline E & 222 & 3 & 225.0 & -13.96 \\
K & 412 & 5 & 529.2 & 12.90 \\
U & 73 & 2 & 242.7 & -6.53 \\
V & 131 & 5 & 502.6 & 4.28 \\
\hline Overall & 838 & & 419.5 & \\
\hline
\end{tabular}

Test

Null Hypothesis

$\mathrm{H}_{0}$ : All medians are equal

Althernative Hypotheses

$\mathrm{H}_{1}$ : At least one median is different

\begin{tabular}{llll} 
Method & DF & H-Value & P-Value \\
\hline Not adjusted for ties & 3 & 282.30 & 0.000 \\
Adjusted for ties & 3 & 290.66 & 0.000 \\
\hline
\end{tabular}

There were differences across cohorts worthy of mention. Ego-defensive and Value-expressive codes increased significantly. Knowledge and Utilitarian codes decreased. Table 11 illustrates the significance. 
TABLE 11

TABULATED STATISTICS: ATTITUDE BY COHORT

Rows: Attitude

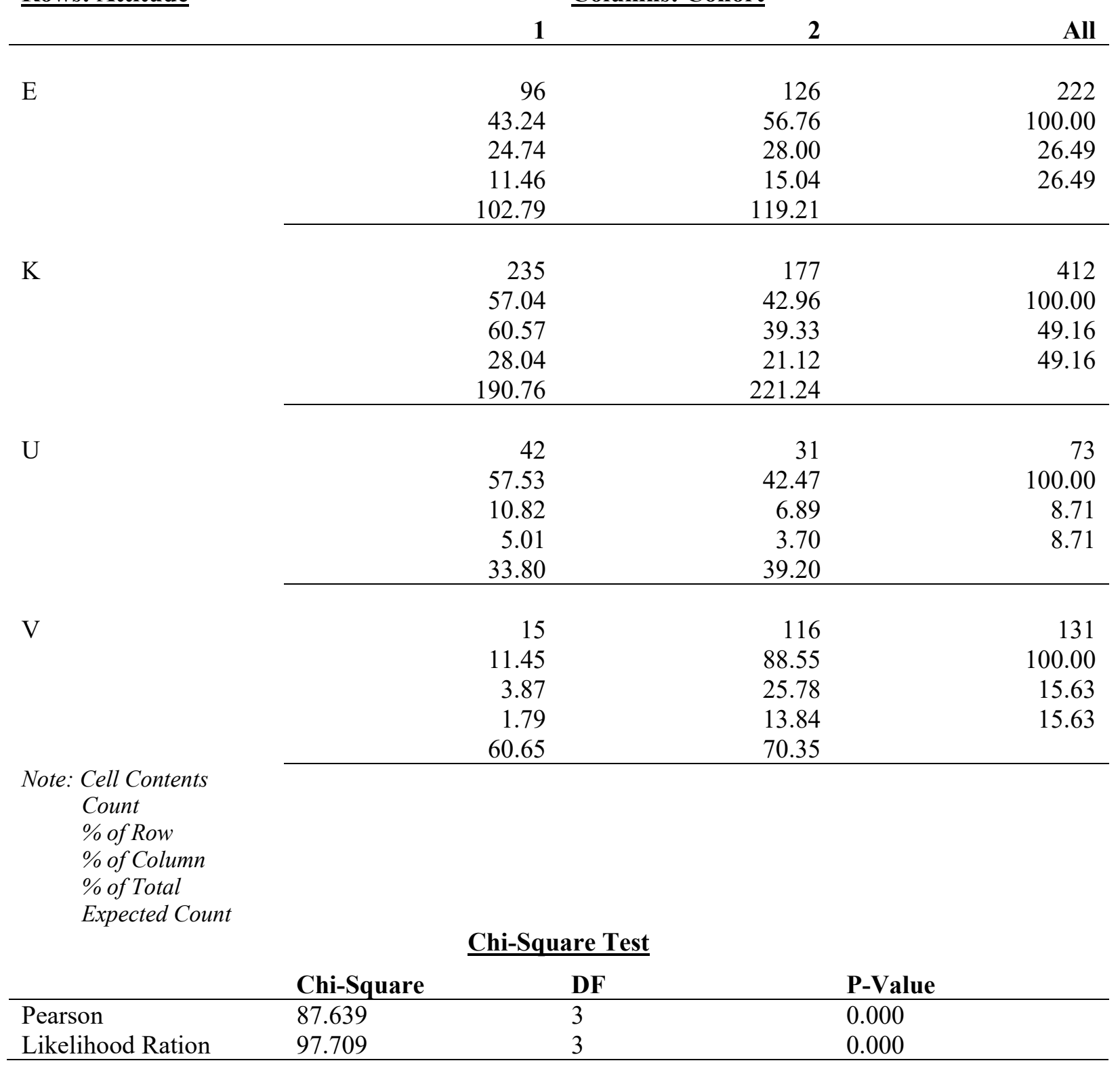

Table 12 provides the descriptive statistics for primary emotion for each cohort. 
TABLE 12

TABULATED STATISTICS: PRIMARY EMOTION BY COHORT

Descriptive Statistics

Rows: Cohort

Columns: Primary emotion

\begin{tabular}{rrrrrrrrrrr} 
& $*$ & ANW & AP & AW & CF & CN & H & J & S & All \\
\hline & & & & & & & & & & \\
1 & 4 & 0 & 6 & 113 & 26 & 189 & 6 & 10 & 34 & 388 \\
& 1.03 & 0.00 & 1.55 & 29.12 & 6.70 & 48.71 & 1.55 & 2.58 & 8.76 & 100.00 \\
& 12.12 & 0.00 & 46.15 & 67.66 & 72.22 & 52.65 & 50.00 & 52.63 & 31.19 & 46.30 \\
& 0.477 & 0.000 & 0.716 & 13.484 & 3.103 & 22.554 & 0.716 & 1.193 & 4.057 & 46.301 \\
\hline \multirow{4}{*}{2} & & & & & & & & & & \\
& 29 & 90 & 7 & 54 & 10 & 170 & 6 & 9 & 75 & 450 \\
& 6.44 & 20.00 & 1.56 & 12.00 & 2.22 & 37.78 & 1.33 & 2.00 & 16.67 & 100.00 \\
& 87.88 & 100.00 & 53.85 & 32.34 & 27.78 & 47.35 & 50.00 & 47.37 & 68.81 & 53.70 \\
& 3.461 & 10.740 & 0.835 & 6.444 & 1.193 & 20.286 & 0.716 & 1.074 & 8.950 & 53.699 \\
\hline & & & & & & & & & & \\
& 33 & 90 & 13 & 167 & 36 & 359 & 12 & 19 & 109 & 838 \\
& 3.94 & 10.74 & 1.55 & 19.93 & 4.30 & 42.84 & 1.43 & 2.27 & 13.01 & 100.00 \\
& 100.00 & 100.00 & 100.00 & 100.00 & 100.00 & 100.00 & 100.00 & 100.00 & 100.00 & 100.00 \\
& 3.938 & 10.740 & 1.551 & 19.928 & 4.296 & 42.840 & 1.432 & 2.267 & 13.007 & 100.000 \\
\hline
\end{tabular}

Note: Cell Contents

Count

$\%$ of Row

$\%$ of Column

$\%$ of Total

Expected Count

Chi-Square Test

\begin{tabular}{llll} 
& Chi-Square & DF & P-Value \\
\hline Pearson & 149.684 & 8 & 0.000 \\
Likelihood Ration & 187.158 & 8 & 0.000 \\
\hline
\end{tabular}

It was evident that contentment was the emotion most clearly associated with ALO attainment. A follow-up Kruskal-Wallis test demonstrated extremely significant differences between GUALS score medians by emotions $H(8,838)=404.80, p=0.00$. Earlier in this report we described an original code, anxiety no worry (ANW). While those coded data seem to have been less detrimental to affective learning, this category, and the originally coded anxiety-worry (AW) both served as barriers to affective learning, as evidenced by Table 13 . 


\section{TABLE 13}

\section{KRUSKAL-WALLIS TEST: GUALS-SCORE VERSUS PRIMARY EMOTION}

\section{$\underline{\text { Descriptive Statistics }}$}

\begin{tabular}{lrrrr} 
Primary_emotion & N & Median & Mean Rank & Z-Value \\
\hline$*$ & 33 & 1 & 145.6 & -6.63 \\
ANW & 90 & 3 & 344.6 & -3.11 \\
AP & 13 & 1 & 55.55 & -5.46 \\
AW & 167 & 3 & 250.4 & -10.09 \\
CF & 36 & 3 & 229.2 & -4.82 \\
CN & 359 & 6 & 602.2 & 18.91 \\
H & 12 & 4 & 389.9 & -0.46 \\
J & 19 & 5 & 445.1 & 0.47 \\
S & 109 & 2 & 327.0 & -4.28 \\
\hline Overall & 838 & & 419.5 & \\
\hline
\end{tabular}

\section{Test}

Null Hypothesis $\quad \mathrm{H}_{0}$ : All medians are equal

Althernative Hypotheses $\quad \mathrm{H}_{1}$ : At least one median is different

\begin{tabular}{llll} 
Method & DF & H-Value & P-Value \\
\hline Not adjusted for ties & 8 & 404.80 & 0.000 \\
Adjusted for ties & 8 & 416.79 & 0.000 \\
\hline
\end{tabular}

Note: all negative emotions with less than 10 coding instances were combined into the * category for final analyses.

The researchers may remove this whimsical code in future projects as we explore fuzzy-set (Rihoux \& Ragin, 2009) data analysis.

Only one item from the Level 1 evaluations had a significant effect on the achievement of ALOs: whether students perceived instructions as clear and easy to follow. Both models indicated strong influence:

- $\quad$ Mixed Effects Model: $F(1,803.61)=27.37, p=0.000$

- General Linear Model: $F(1,831)=8.88, p=0.003$

A follow-up Kruskal-Wallis test revealed significant $H(3,386)=88.76, p=0.00$ differences in GUALS score medians (see Table 14).

TABLE 14

KRUSKAL-WALLIS TEST: GUALS-SCORE VERSUS RECORDED CLEAR INSTRUCTIONS

\begin{tabular}{lrrrr} 
Recorded Clear Instructions & N & Median & Mean Rank & Z-Value \\
$*$ & 2 & 4 & 413.0 & -0.013 \\
1 - Completely Disagree & 31 & 3 & 296.9 & -2.86 \\
2 - Moderately Disagree & 103 & 3 & 306.0 & -5.05 \\
3 - Moderately Agree & 330 & 4 & 394.9 & -2.28 \\
4 - Completely Agree & 370 & 5 & 481.1 & 6.68 \\
\hline Overall & 836 & & 418.5 & \\
\hline
\end{tabular}

\section{Test}

Null Hypothesis $\quad \mathrm{H}_{0}$ : All medians are equal

Althernative Hypotheses $\quad \mathrm{H}_{1}$ : At least one median is different

\begin{tabular}{llll} 
Method & DF & H-Value & P-Value \\
\hline Not adjusted for ties & 4 & 58.22 & 0.000 \\
Adjusted for ties & 4 & 59.95 & 0.000
\end{tabular}

Adjusted for ties

The chi-square approximation may not be accurate when some people sample sizes are less than 5.

Note: * represents missing data in this table. 


\section{DISCUSSION}

There are several significant outcomes that may help as classroom instructors consider implementing affective learning in their own classrooms. One finding illustrated the degree of control instructors may have over learning - including the power to unintentionally suppress learning outcomes. The GUALS, as an instrument for assessing affective learning, provided meaningful data and is discussed further. Certain emotions and attitudes seem to have powerful effects on learning outcomes; the data are enlightening and may provide useful insights on varied approaches for online learning instructors.

\section{Clear Instructions for Discussions and Assignments Are Critical}

This is by far the most powerful and practical piece of advice that has emerged from this research. When course designers write instructions that are specifically aimed at learners (rather than for us, the subject-matter experts), affective learning increases. Clear step-by-step instructions, as opposed to general instructional prompts, seem to increase attainment of ALOs. This variable - clear instructions from the learner's perspective - might also be of interest to researchers studying cognitive learning outcome attainment. The learning activities and instructions in this course were reviewed by Quality Matters-trained evaluators, but students still struggled with understanding some of the instructions for assignments. This is the one variable that is completely under instructors' control: we may choose to employ clear instructions and strengthen our online coursework or take a cavalier attitude toward clarity to the detriment of our students. The strategic implications of ignoring this finding are disastrous for online learning, as many have experienced during the ongoing pandemic.

\section{The GUALS Is a Reliable Instrument for Assessing Affective Learning Outcomes}

The agreement achieved across raters was acceptable, but only marginally so with respect to coding for evidence of affective learning as a binary variable. The researchers discussed the discrepancies and agreed on the adjusted (0/1) codes used in the data analysis. Greater mutual understanding was achieved through those discussions and negotiations. Intertwined with and subsequent to that discussion was the discovery of the GUALS instrument. The researchers believed a collective understanding of the dependent variable affective learning had been achieved before assessing and then assigning GUALS scores. That the team of coders achieved such a high level of agreement on admittedly subjective assessments provides sound evidence for continued research with the GUALS (Rogers et al., 2018) instrument.

\section{Qualitative Analysis Provided Strong Evidence of Emotional and Attitudinal Regulation of Learning}

Contentment is the emotion that was most associated with higher-level affective learning in this study. Researchers characterize contentment as a deeper, secure understanding within oneself that learning has occurred, and that one is sufficiently competent to handle the issues at hand (Abdel-Magid, 2017; Shaver et al., 2001). Subsequently, characterization is possible; indeed, several students demonstrated contentment with having learned enough from the course to characterize their respective organizations. Future discussions and assignments should attempt to double as catalysts for forming and developing contentment.

Attitudinal shifts across the cohorts were salient, though, and other noticeable differences across cohorts were significant $X^{2}(8, N=838)=149.68 . p=.000$. In particular, researchers found it interesting that value-expressive and ego-defensive attitude codes increased to the extent observed. Additional qualitative analysis and qualitizing revealed that those codes were most associated with events extrinsic to the course itself, primarily weather/climate disasters and/or significant familial COVID-related disruptions in students' lives. Perhaps fuzzy-set qualitative content analysis (fsQCA) would be of use for digging deeper into such data sets. 


\section{SUMMARY AND RECOMMENDATIONS}

As neoliberalism continually encroaches on academic spaces, responsible faculty members are expected to consider program-graduates' future market values, and departments that include coursework incorporating career preparation are seeking competitive advantages for their graduates. Despite departmental- and program-specific prestige goals, faculty members must accommodate students' individual life-goals in their planning. There is a need to delicately balance the collaborative nature of Salmon's fifth-stage learning outcomes with the widely held perception that instructors who relinquish absolute control over their curricula inevitably offer less rigorous coursework - and, by extension, produce less desirable graduates. Most students across cohorts were striving to increase their leadership responsibilities; however, some student comments indicated that they were not career-focused with respect to changing positions within an organization. Rather, they saw the EdD degree as just a piece of paper that is necessary to advance to the next rung of the pay-increase ladder. From that viewpoint, the course went far beyond what they intended or expected to learn, and they helped guide adjustments to the curriculum to better fit with their professional needs. Similarly, discussion with matriculated students (cohort one) was used to fine-tune material for subsequent offerings; the process repeated with cohort two. It is not the subject of this report, but there were modest improvements across all categories of the Level 1 formative assessment data from cohort 1 to cohort 2.

\section{Recommendations}

Employed Graduates From Programs Which Implemented ALOs Should Be of Great Interest to AffectiveLearning Studies

Level-3 and -4 evaluations have great potential as areas for future research. A wide array of affectivelearning constructs (e.g., self-leadership (Neck, Manz, \& Houghton, 2019), the impact of emotional intelligence (Dabke, 2016), spirituality (Houghton, Neck, \& Krishnaskumar, 2016), mindset (Dweck, 2006; Yeager \& Dweck, 2012), and grit (Duckworth, 2020; Duckworth \& Gross, 2014)) are all related to-and perhaps key components of-affect. As this study suggests, looking deeply into how attitudes may be triggered and how they might be circumvented seems to be a topic that is ripe for research. Investigating the relationships between these additional psychological constructs and affect should provide fertile ground for future projects. For-credit coursework is not the only arena of interest, either; specialists are increasingly turning to free massive open online courses (MOOCs) for professional development. As $\mathrm{Wu}, \mathrm{Kao}, \mathrm{Wu}, \&$ Wei (2019) demonstrated, ALOs are necessarily an increasingly critical aspect of entrepreneurial development.

\section{The Time Is Ripe for a Resurgence in Ethnomethodological Studies}

If there be a silver research-lining to be found in 2020, it is that the ongoing COVID-19 pandemic may be a great "breach-event." Simply put, lives were disrupted, and change ensued. Earlier in the report we referred to the deceptively simple Table 2 , which illustrated how men are achieving affective learning outcomes slightly higher than women. By analyzing the weekly reflections from an ethnomethodological (Garfinkel, 1967) perspective we were able to see that a majority of restorative work was and is being done by women, for their families, even though they are also full-time professionals. The reflections of men were still focused on organizational restorations, while women were generally preoccupied with moving their roles online and homeschooling their own children. Traditional notions of roles are still heavily at play in this slice of society. The researchers believe that ethnomethodological analyses should increase since the whole of the planet is engaged in restorative actions. Organizational- and business- anthropological lenses may also enlighten researchers as we re-evaluate designs available for qualitative methodology. Affective learning and affective attributes contribute to a research area for which fsQCA may enhance researchers' understandings of students' reality. 
Dialogic Advising May Catalyze Powerful Learning and Retention Mediation

Using principles of Dialogic OD (Bushe \& Marshak, 2015) as students were reflecting, instructors as well as advisors who are so inclined may alter the learning paradigm. Instructors are able, if willing, to feel the authenticity of the student; as Nix, et al (2015) demonstrated, forging authentic connections between instructors and students enhances attainment of cognitive and affective learning outcomes. As evidenced earlier in the report, analysis of this data may be challenging. Rihoux \& Ragin (2009) demonstrated the feasibility of calibrating partial membership in categorical and ordinal variables. Attitudinal and emotional conditions do not fit neatly into categories, nor do they always fit the set-between-all-sets we created to make them accountable. This universe of research is fraught with dichotomous galaxies orbiting trichotomous stars. However, they either stunt or catalyze learning. The researchers recoded and condensed into three categories, negative emotions, positive emotions, and confusion. Table 15 provides a closing snapshot for researchers, instructors, and advisors to consider.

TABLE 15

KRUSKAL-WALLIS TEST: GUALS-SCORE VERSUS RECODED PRIMARY EMOTION

\section{$\underline{\text { Descriptive Statistics }}$}

\begin{tabular}{lrrrr} 
Recorded Primary_emotion & N & Median & Mean Rank & Z-Value \\
\hline Negative Emotions & 303 & 3 & 258.6 & -14.48 \\
Confusion & 36 & 3 & 229.2 & -4.82 \\
Positive Emotions & 499 & 5 & 530.9 & 16.17 \\
\hline Overall & 838 & & 419.5 & \\
\hline
\end{tabular}

Test

Null Hypothesis $\quad \mathrm{H}_{0}$ : All medians are equal

Althernative Hypotheses $\quad \mathrm{H}_{1}$ : At least one median is different

\begin{tabular}{llll} 
Method & DF & H-Value & P-Value \\
\hline Not adjusted for ties & 2 & 261.89 & 0.000 \\
Adjusted for ties & 2 & 269.65 & 0.000 \\
\hline
\end{tabular}

Affective learning goals should represent internalized values attitudes and emotions that impact behavior over extended periods of time. Assessing affective learning is time-consuming and its outcomes are not easily evaluated (Pascarella, 1985); consequently, most coursework has generally neglected them in favor of more easily quantified cognitive and/or psychomotor learning outcomes. It is well past time to change.

\section{ACKNOWLEDGEMENTS}

The authors would like to thank Demian Pedone for copy-editing.

\section{REFERENCES}

Abdel-Magid, M.I.M. (2017). The tree of emotions: Exploring the relationships of basic human emotions. International Journal of Indian Psychology, 5(1), 22-37.

Arora, S., \& Sharma, R. (2018). Positive affect, psychotherapy, and depression. Indian Journal of Psychiatry, 60(2), 199-204.

Baumeister, R.F., \& Bushman, B.J. (2007). Angry emotions and aggressive behaviors. In G. Steffgen \& M. Gollwitzer (Eds.), Emotions and aggressive behavior (pp. 61-75). Hogrefe \& Huber Publishers. 
Bowman, N.A. (2010). Can 1st-year college students accurately report their learning and development? American Educational Research Journal, 47, 466-496.

Bushe, G.R., \& Marshak, R.J. (2015). Dialogic organization development: The theory and practice of transformational change. Oakland, CA: Berrett-Koehler Publishers, a BK Business Book.

Clark, M.S., \& Fiske, S.T. (1982). Affect and cognition. Erlbaum.

Dabke, D. (2016). Impact of leader's emotional intelligence and transformational behavior on perceived leadership effectiveness: A multiple source view. Business Perspectives and Research, 4(1), 27 40.

De Bono, E. (1985). Six Thinking Hats. Little, Brown, and Company.

Debono, K.G. (1987). Investigating the social-adjustive and value-expressive functions of attitudes: Implications for persuasion processes. Journal of Personality and Social Psychology, 52, 279287.

Debono, K.G. (2000). Attitude functions and consumer psychology: Understanding perceptions of product quality. In G.R. Maio \& J.M. Olson (Eds.), Why we evaluate: Functions of attitudes (pp. 195-221). Erlbaum.

Duckworth, A.L. (2020). Grit Scale. Retrieved from https://angeladuckworth.com/grit-scale/

Duckworth, A.L., \& Gross, J.J. (2014). Self-control and grit: Related but separable determinants of success. Current Directions in Psychological Science, 23, 319-325.

Dweck, C.S. (2006). Mindset: The new psychology of success. Random House Inc.

Garfinkel, H. (1967). Studies in ethnomethodology. Prentice-Hall: Englewood Cliffs.

Gatignon, H., Tushman, M.L., Smith, W., \& Anderson, P. (2002). A structural approach to assessing innovation: Construct development of innovation locus, type, and characteristics. Management Science, 48, 1103-1122. https://doi.org/10.1287/mnsc.48.9.1103.174

Goleman, D. (1987, August 25). Embattled Giant of Psychology Speaks His Mind. New York Times. Retrieved from https://www.nytimes.com/1987/08/25/science/embattled-giant-of-psychologyspeaks-his-mind.html

Gredler, M.E. (2009). Learning and instruction: Theory into practice. Upper Saddle River, NJ [u. a.: Merrill.

Hansen, M. (2019). Using assessment trends in planning, decision-making, and improvement. In S.P. Hundley, S. Kahn, \& T.W. Banta (Eds.), Trends in assessment: Ideas, opportunities, and issues for higher education (Chapter 11). Stylus Publishing.

Herek, G.M. (1986). The instrumentality of attitudes: Toward a neofunctional theory. Journal of Social Issues, 42, 99-114.

Herek, G.M. (1987). Can functions be measured? A new perspective on the functional approach to attitudes. Social Psychology Quarterly, 50, 285-303.

Herek, G.M. (2000). The social construction of attitudes: Functional consensus and divergence in the U.S. public's reactions to AIDS. In G.R. Maio \& J.M. Olson (Eds.), Why we evaluate: Functions of attitudes (pp. 325-364). Erlbaum.

Hooker, J., \& Denker, K. (2014). The learning loss scale as an assessment tool: An empirical examination of convergent validity with performative measures. Communication Teacher, 28, 130-143.

Houghton, J.D., Neck, C.P., \& Krishnaskumar, S. (2016). The what, why, and how of spirituality in the workplace revisited: A 14-year update and extension. Journal of Management, Spirituality \& Religion, 13(3), 177-205. https://doi.org/10.1080/14766086.2016.1185292

Hundley, S.P., Kahn, S., Barbee, J., \& Partners of the Assessment Institute. (2019). Meta-trends in assessment: Perspectives, analyses, and future directions. In S.P. Hundley, S. Kahn, \& T.W. Banta, Trends in assessment: Ideas, opportunities, and issues for higher education (Chapter 12). Stylus Publishing.

Immordino-Yang, M.H., \& Damasio, A.R. (2007). We feel therefore we learn: The relevance of affective and social neuroscience to education. Mind, Brain, and Education, 1(1), 3-10.

https://doi.org/10.1111/j.1751-228X.2007.00004.x 
Izard, C.E. (2010). The many meanings/aspects of emotion: Definitions, functions, activation, and regulation. Emotion Review, 2(4), 363-370.

Katz, D. (1960). The functional approach to the study of attitudes. Public Opinion Quarterly, 24, 163204.

Kilgo, C.A., Ezell Sheets, J.K., \& Pascarella, E.T. (2015). The link between high-impact practices and student learning: Some longitudinal evidence. Journal of Higher Education and Educational Planning, 69(4), 509-525. https://doi.org/10.1007/s10734-014-9788-z

Kincheloe, J. (2008). Critical constructivism primer. Peter Lang.

Kirkpatrick, D. (1994). Evaluating training programs: The four levels. Berrett-Koehler.

Kovbasyuk, O., \& Blessinger, P. (2013). Meaning-centered education: International perspectives and explorations in higher education. Routledge.

Krathwohl, D.R., Bloom, B.S., \& Masia, B.B. (1964). Taxonomy of educational objectives, Handbook II: Affective domain. David McKay Company, Inc.

Locander, W.B., \& Spivey, W.A. (1978). A functional approach to attitude measurement. Journal of Marketing Research, 15, 576-587.

Messman, S.J., \& Jones-Corley, J. (2001). Effects of communication environment, immediacy, and communication apprehension on cognitive and affective learning. Communication Monographs, 68, 184-200. https://doi.org/10.1080/03637750128054

McCroskey, J.C. (1994). Assessment of affect toward communication and affect toward instruction in communication. In S. Morreale \& M. Brooks (Eds.), 1994 SCA summer conference proceedings and prepared remarks: Assessing college student competence in speech communication (pp. 5668). Speech Communication Association.

NCHEMS (National Center for Higher Education Management Systems). (2000). The competency standards project: Another approach to accreditation review. Council for Higher Education Accreditation.

Neck, C.P., Manz, C.C., \& Houghton, J.D. (2019). Self-leadership: The definitive guide to personal excellence ( $2^{\text {nd }}$ ed). Sage.

Nix, J.V., Shelton, V.K., \& Song, L.M. (in press). Implementing affective learning outcomes through a meaning-centered curriculum. In E. Kapur \& P. Blessinger (Eds.), ICT and innovation in teaching learning methods in higher education. Emerald.

Nix, J.V., \& Song, L.M. (2020). Affective assessment: Incorporating emotions into our work for social justice. Proceedings of the Association for Assessment of Learning in Higher Education (AALHE), 2020 Annual Conference.

Nix, J.V., Lion, R.W., Michalak, M., \& Christensen, A. (2015). Individualized, purposeful, and persistent: Successful transitions and retention of students at risk. Journal of Student Affairs Research \& Practice, 52(1).

Norris, K., \& Weiss, H.A. (2019) Assessing community engagement. In S.P. Hundley, S. Kahn, \& T.W. Banta, Trends in assessment: Ideas, opportunities, and issues for higher education (Chapter 4). Stylus Publishing.

Ortony, A., \& Turner, T.J. (1990). What's basic about basic emotions? Psychological Review, 97, 315331.

Pascarella, E.T. (1985). Students' affective development within the college environment. Journal of Higher Education, 56, 640-663. 10.2307/1981072

Pekrun, R., \& Linnenbrink-Garcia, L. (Eds.). (2014). International handbook of emotions in education. Routledge.

Petty, R.E., \& Wegener, D.T. (1998). Matching versus mismatching attitude functions: Implications for scrutiny of persuasive messages. Personality and Social Psychology Bulletin, 24, 227-240.

Rihoux, B., \& Ragin, C.C. (2009). Configurational comparative methods: Qualitative comparative analysis (QCA) and related techniques. Sage Publications, Inc.

Rogers, G., Mey, A., Chan, P., Lombard, M., \& Miller, F. (2018). Development and validation of the Griffith University Affective Learning Scale (GUALS): A tool for assessing affective learning in 
health professional students' reflective journals. MdeEdPublish, 1. Retrieved from https://www.mededpublish.org/manuscripts/1361

Salkind, N.J. (2010). Encyclopedia of research design (Vols. 1-0). SAGE Publications, Inc. Doi: $10.4135 / 9781412961288$

Salmon, G. (2013). E-tivities: The key to active online learning ( $2^{\text {nd }}$ ed.). Routledge, Taylor \& Francis Group.

Schneider, M., \& Preckel, F. (2017). Variables associated with achievement in higher education: A systematic review of meta-analyses. Psychological Bulletin, 143, 565-600. https://doi/10.1037/bul0000098

Seels, B., \& Glasgow, Z. (1990). Exercises in instructional design. Merril.

Shaver, P., Schwartz, J., Kirson, D., \& O’Connor, C. (2001). Emotional knowledge: Further exploration of a prototype approach. In G. Parrott (Ed.), Emotions in social psychology: Essential readings (pp. 26-56). Psychology Press.

Shavitt, S. (1990). The role of attitude objects in attitude functions. Journal of Experimental Social Psychology, 26, 124-148.

Shavitt, S., Swan, S., Lowrey, T.M., \& Wanke, M. (1994). The interaction of endorser attractiveness and involvement in persuasion depends on the goal that guides message processing. Journal of Consumer Psychology, 3, 137-162.

Simonson, M., Smaldino, S., \& Zvacek, S. (2015). Teaching and learning at a distance: Foundations of distance education ( $6^{\text {th }}$ ed.). IAP.

Smith, M.B., Bruner, J.S., \& White, R.W. (1956). Opinions and personality. Wiley.

Snyder, M., \& DeBono, K.G. (1985). Appeals to image and claims about quality: Understanding the psychology of advertising. Journal of Personality and Social Psychology, 49, 586-597.

Spady, G.W. (1994). Outcome-based education: Critical issues and answers. The American Association of School Administrators.

Tyng, C.M., Amin, H.U., Saad, M.N.M., \& Malik, A.S. (2017). The influences of emotion on learning and memory. Frontiers in Psychology, 8, 1-22, 1454. https://doi.org/10.3389/fpsyg.2017.01454

Witt, P.W., Wheeless, L.R., \& Allen, M. (2004). A meta-analytic review of the relationship between teacher immediacy and student learning. Communication Monographs, 71, 184-207.

Wu, W.H., Kao, H.Y., Wu, S.H., \& Wei, C.W. (2019). Development and evaluation of affective domain using student's feedback in entrepreneurial massive open online courses. Frontiers in Psychology, 10, 1109-1117. https://doi.org/10.3389/fpsyg.2019.01109

Yeager, D.S., \& Dweck, C.S. (2012). Mindsets that promote resilience: When students believe that personal characteristics can be developed. Educational Psychologist, 47(4), 302-314.

Zahl, S.B., Jimenez, S., \& Huffman, M. (2019). Assessment at the highest degree(s): Trends in graduate and professional education. In S.P. Hundley, S. Kahn, \& T.W. Banta, Trends in assessment: Ideas, opportunities, and issues for higher education (Chapter 7). Stylus Publishing.

\section{APPENDIX}

\section{Nomenclature}

Affect

According to Krathwohl et al., 1964, "a collection of values or value sets" (pp 164-165). Affect has been classified by researchers into three categories, as either constructive, positive, or contrary (Arora \& Sharma, 2018). An example of a long-term contrary affective disorder is depression.

Assessment

The act of qualifying or quantifying the amount, value, quality, or importance of student learning.

Attitudes

Reflections of a state of mind, a disposition, or an affect. 


\section{Emotions}

Baumeister and Bushman (2007) conceptualized the experience of an emotion as "a subjective state, often accompanied by a bodily reaction (e.g., increased heart rate) and an evaluative response... to some event" (p. 61). Emotions include reactions and judgments as interactive core elements.

\section{Ethnomethodology}

A type of inquiry based on the premise that reality is knowable only when restored to order after a breach event. The only way to know and understand reality is to observe the restorative actions of participants as they once again make their actions reportable and accountable.

\section{Evaluations}

Assessing a program, activity (such as academic coursework), or other entity (including persons) through application of a standardized set of assessments. This authors also here utilize the construct of evaluation as practiced by human resources development (HRD) professionals.

\section{Phenomenology}

A type of inquiry based on the premise that reality is constructed by individuals and is not collectively understood nor is it objectively agreed-upon.

\section{Values}

The beliefs and mental/emotional constructs that motivate a person or organization and inform their actions. We generally see values reflected in individual or organizational behavior. For example, a budget would be an organizational values document-or direct-evidence of organizational values. 